\title{
PZT Thin-Film Meso- and Micro Devices
}

\author{
I. Y. (STEVE) SHEN, ${ }^{1, *}$ G. Z. CAO,${ }^{2}$ CHIA-CHE WU, ${ }^{3}$ \\ AND CHENG-CHUN LEE ${ }^{1}$
}
${ }^{1}$ Department of Mechanical Engineering, University of Washington, Seattle, WA 98195-2600, USA
${ }^{2}$ Department of Material Science and Engineering, University of Washington, Seattle, WA 98195-2120, USA
${ }^{3}$ Department of Mechanical Engineering, National Chung-Hsien University, Taichung, Taiwan

\begin{abstract}
This paper consists of three major topics. The first topic is a review of challenges encountered in PZT thin film fabrication. Currently, sol-gel processing is one of the most promising techniques to fabricate PZT thin films. There are, however, several major challenges, including crack formation, thermally unstable electrodes, and poor piezoelectric properties. The second topic reveals some innovative fabrication processes that could substantially enhance quality of PZT thin films. For example, use of dilute sealant layer and rapid thermal annealing can lead to PZT films with large crack-free area. Use of sol electrophoretic deposition can enhance piezoelectric properties and thickness of PZT films simultaneously. Use of sol electrophoresis and soft lithography can directly pattern PZT films without etching. The third topic is design considerations encountered in the development of PZT thin-film microactuators. For example, one needs to confirm that the corner frequency of the PZT RC-circuit is much higher than the lowest natural frequency of the actuator's mechanical structure, so that the bandwidth and quality factor will not be sacrificed. Also, accuracy of finite element analyses cannot be readily assumed, because uncertainties in piezoelectric constants and boundary conditions can significantly alter the predictions from the finite element analyses.
\end{abstract}

Keywords PZT thin films; sol-gel process; sol electrophoresis; soft lithography; microactuators; piezoelectric constants; corner frequencies; bandwidth; quality factor; finite element analysis

\section{Introduction}

Lead-Zirconium-Titanium Oxide $\left(\mathrm{PbZr}_{1-\mathrm{x}} \mathrm{Ti}_{\mathrm{x}} \mathrm{O}_{3}\right.$ or PZT) is a piezoelectric material widely used as sensors and actuators for bulk structures. Advantages of PZT-based devices include high frequency bandwidth, fast response, and high sensitivity. Miniaturization of PZT-based devices will not only perfect many existing products, but also open vast new applications in various areas, such as active read/write heads for disk drives, tiny biomedical diagnostic tools, minute hearing implants, and miniaturized surgical tools that are less invasive [1-5].

As a concrete example, recent development of next-generation scanning endoscopes calls for high-performance PZT thin-film actuators. Traditional endoscopes have large

Received March 24, 2005; in final form April 27, 2005.

*Corresponding author. E-mail: ishen@u.washington.edu 


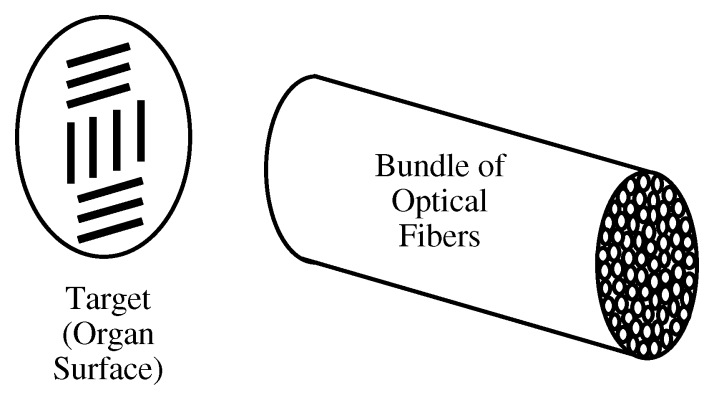

Figure 1. Setup of current endoscopes.

diameter (about the size of a vitamin pill), because they use a bundle of optical fibers to image organ surfaces; see Fig. 1. As a result, traditional endoscopes have two severe drawbacks. First, traditional endoscopes can only probe organs with large openings, such as stomach. Moreover, use of endoscopes requires general anesthesia. The second drawback is that traditional endoscopes cannot be sterilized because the optical fibers are fragile. The general practice is to disinfect the endoscopes. Therefore, there is a strong need in the medical community to develop minute endoscopes for sensitive tracts (e.g., bronchia) and disposable endoscopes for sanitary reasons.

Figure 2 shows the central piece of a next-generation, minute, disposable endoscope [5]. The overall size of the endoscope is less than $1 \mathrm{~mm}$ in diameter and $5 \mathrm{~mm}$ in length. The major component is a single optical fiber; therefore, the size of the endoscopes can be dramatically reduced. At the end of the optical fiber, a minute resonator drives the optical fiber scanning through the two-dimensional surface to obtain the image. (Dimension specification of the resonator is less than $800 \mu \mathrm{m}$ in diameter.) A major technical challenge is to find a minute actuator that has large enough actuation strength while scanning at a high frequency, such as $5-15 \mathrm{kHz}$ or more. According to [6], there are four types of microactuators: thermal [7-10], shape-memory-alloy (SMA) [6], electrostatic [11-12], and piezoelectric (specifically PZT) [13-16]. Thermal and SMA actuators have low frequency bandwidth [6] $(<1 \mathrm{kHz})$, whereas electrostatic and PZT actuators have high frequency bandwidth $(>1 \mathrm{kHz})$. Moreover, electrostatic actuators have much smaller actuation force and energy density than PZT films $\left(3.4 \times 10^{3} \mathrm{~J} / \mathrm{m}^{3}\right.$ for electrostatic actuators vs. $1.2 \times$ $10^{5} \mathrm{~J} / \mathrm{m}^{3}$ for PZT [6]). Based on these considerations, the best design choice for the nextgeneration scanning endoscopes is PZT microactuators.

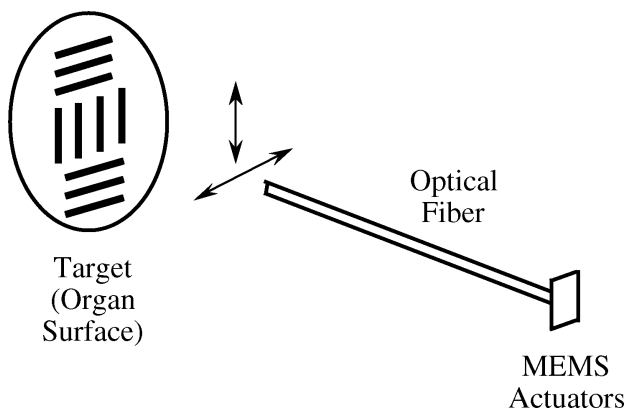

Figure 2. Setup of future endoscopes. 
Despite the needs for PZT microactuators, miniaturization of bulk PZT actuators into millimeter or micron ranges is not trivial [13-16]. Traditional bulk PZT often appears as thin patches with thickness no less than $80 \mu \mathrm{m}$ [17]. These bulk PZT patches, however, cannot be easily integrated into microactuators for several reasons. First, PZT is ceramic and is very brittle; therefore, it is difficult to machine it into a small chip with accurate dimensions such as $300 \mu \mathrm{m} \times 300 \mu \mathrm{m}$ and to assemble it onto microactuator substrate. Second, direct use of bulk PZT in microactuators will lead to poor aspect ratios degrading actuator performance. For example, the bulk PZT patches have thickness of $80 \mu \mathrm{m}$, whereas the microacutuator substrate may only have thickness of $40 \mu \mathrm{m}$. In this case, the use of the bulk PZT triples the actuator thickness to $120 \mu \mathrm{m}$. As a result, the overall stiffness increases substantially shifting natural frequencies and reducing the gain and the quality factor of the microactuator. Therefore, a better way to implement PZT microactuators is to use PZT films whose thickness is one order of magnitude less than that of bulk PZT patches. For example, a pilot study of dual-stage PZT actuators for disk drives calls for PZT films with thickness of $2.5 \mu \mathrm{m}$ [18].

In designing PZT microactuators, thickness of the PZT films is a critical parameter and can vary substantially from one microactuator design to another. In general, use of thicker PZT films will result in larger actuation strength and higher frequency bandwidth. Thicker PZT films, however, will require larger voltage (and power) to actuate. All things considered, successful development of PZT microactuators requires PZT thin films with a wide range of film thickness.

Currently, successful processes of PZT films include sputtering [19-23], direct bonding [24-25], screen printing [26-27], metallorganic chemical vapor deposition (MOCVD) [28], and sol-gel processing [29-35]. (Also, pulsed laser deposition could be a possible way to make PZT films.) So far, MOCVD and sol-gel processing are proven to be the most promising techniques for the fabrication of PZT thin films. MOCVD offers several advantages including conformal coverage, columnar microstructures, and no needs for post-deposition annealing [28]. In comparison, sol-gel processing offers four unique advantages. First, it is easy to control the stoichiometric chemical composition of PZT films. This is extremely important for complex oxides such as PZT, because their physical properties strongly depend on the precise control of the chemical composition. Second, sol-gel processing is inexpensive, due to its $100 \%$ usage of precursors. Third, sol-gel processing is suitable for mass production and compatible with device fabrication processes. Lastly, sol-gel processing promises direct patterning of microstructures without using conventional etching. Based on these factors, it is more beneficial to fabricate PZT films using sol-gel processing.

\section{Challenges}

Although sol-gel processes have been successfully used for many years, there remain tremendous challenges to overcome. To properly explain these challenges, let's first describe typical sol-gel processes for PZT thin films; see Fig. 3. The first step is to deposit bottom electrode on silicon substrate. The second step is to dip-coat or spin-coat PZT sol onto the substrate. (The PZT sol consists of non-soluble Pb, Zr, and Ti nano-clusters with desired stroichiometry and molecular level homogeneity dispersed in solvent.) As the solvent evaporates from the sol, the condensation process facilitates cross-linking of individual clusters in PZT sol resulting in the sol-gel transition, which is followed with further shrinkage and solidification. Third, the PZT/silicon structure is sintered at high temperature to densify the PZT film and to form the desired perovskite crystalline phase. The sintering 
(a)

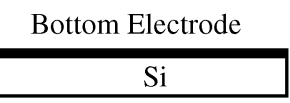

(b)

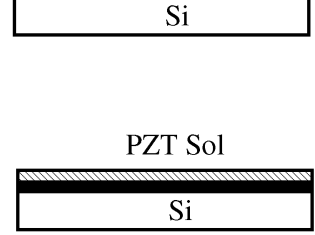

PZT Thin Film

(c)

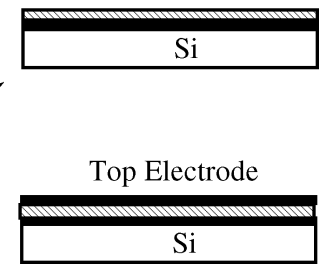

Figure 3. Sol-gel process for PZT thin films.

temperature ranges from $600^{\circ} \mathrm{C}$ to $700^{\circ} \mathrm{C}$, and the sintering time can last from 4 to 6 hours. Finally, the top electrode is deposited.

There are three technical challenges in developing high-performance sol-gel derived PZT films. The first challenge is defects, such as cracks and delamination. The presence of cracks can not only short-circuit the top and bottom electrodes, but also cause aging and fracture of PZT films. In general, delamination results from mismatch of coefficient of thermal expansion (CTE) between the bottom electrode and the PZT film. When the PZT film and the electrode are cooled down from the elevated sintering temperature, significant shear stresses develop at the PZT/electrode interface due to CTE mismatch and cause the delamination. In contrast, cracks primarily result from stress gradients developed during the drying stage. As the solvent evaporates, the concentration of the solid increases and the condensation reaction proceeds to form a 3-dimensional gel network. Further removal of the solvent leads to shrinkage of the gel network driven by the capillary force. As the solvent removes only from the film surface, there is a large stress gradient. When such a stress gradient exceeds the mechanical strength of the gel network, cracks would form. Obviously, cracks are much more likely to develop as the film thickness increases.

Currently, successful research results are primarily for PZT films with thickness less than $1 \mu \mathrm{m}$ [36-38]. Often, these PZT films consist of multiple coatings, with each coating ranging from $15 \mathrm{~nm}$ to $100 \mathrm{~nm}$ in thickness. The corresponding crack-free area is usually about $1 \mathrm{~mm}^{2}$ [36-38]. Hypothetically, one could diligently use 50 coatings to fabricate a PZT film with thickness of $5 \mu \mathrm{m}$. In reality, when the PZT film thickness exceeds $1 \mu \mathrm{m}$ via multiple coating, cracks are so densely populated and the crack-free area is so tiny that the PZT film becomes virtually useless. This is why sol-gel-based fabrication of crack-free PZT films with thickness ranging from $1 \mu \mathrm{m}$ to $30 \mu \mathrm{m}$ remains open thus far. A revolutionary way is needed to fabricate crack-free PZT films in this thickness range. This forms a major limitation to the development of PZT thin-film meso- and micro devices, because a lot of these devices require thickness in this range and large area of crack-free PZT films.

The second challenge is the bottom electrodes. Currently, the bottom electrodes could be metal (e.g., Pt/Ti) or oxide (e.g., $\mathrm{RuO}_{2}$ ). Metal electrodes are widely used, and appear in many devices. Moreover, metal electrodes demonstrate excellent adhesion with PZT films and provide desired diffusion barrier. Metal electrodes, however, become thermally unstable when sintered above $600^{\circ} \mathrm{C}$. The instability results in holes (or porosity) in the electrodes [39]; see the dark areas in Fig. 4. The presence of the holes degrades the functions of the electrodes as an adhesion layer and a diffusion barrier, because the oxygen in the PZT films can diffuse into the substrate causing dielectric loss and fatigue [40-41]. Besides, metal electrodes have very different coefficients of thermal expansion (CTE) from PZT. The significant mismatch of CTE often cracks the PZT films, especially when the film thickness exceeds $1 \mu \mathrm{m}$. In contrast, oxide electrodes have less mismatch of CTE and 


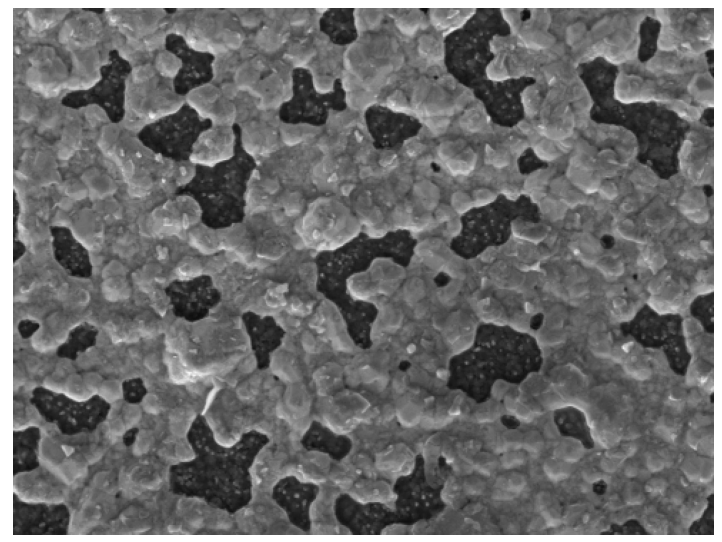

Figure 4. Thermodynamic instability of $\mathrm{Pt} / \mathrm{Ti}$ electrodes, $750^{\circ} \mathrm{C}$ for 1 hour.

better adhesion properties. Oxide electrodes, however, offer poor diffusion barriers, because oxide electrodes can diffuse into PZT films changing the chemical composition of PZT. As a result, the leakage current occurs, breakdown voltage and polarization performance are substantially reduced, and two undesired pyrochlore phases can appear in the PZT films [42]. On the whole, a thermally stable electrode that has small CTE mismatch, good adhesion, and diffusion barrier remains open at this time.

The third challenge is the sintering temperature. Elevation of the sintering temperature will substantially improve the piezoelectric properties of the films. (Ideally, PZT films should have piezoelectric constants comparable to those of bulk PZT.) When the sintering temperature is at $650^{\circ} \mathrm{C}$, the grain size of PZT film is relatively small. For PZT crystalline particles, the piezoelectric effect diminishes as the grain size decreases. Elevation of the sintering temperature to $800^{\circ} \mathrm{C}$, for example, will increase the grain size and enhance the piezoelectric properties significantly. The elevated sintering temperature, however, will cause several adverse effects. First, it will substantially increase the chance to delaminate the PZT films, because higher sintering temperatures causes higher thermal stresses from CTE mismatch. Second, elevation of sintering temperature will accelerate the thermal instability of metal electrodes. Third, elevated sintering temperature will cause the loss of $\mathrm{PbO}$ due to its volatility [43], which may cause serious degradation of piezoelectricity or fatigue [44].

\section{Novel Sol-Gel Processes for PZT Thin Films: Dilute Sealant Coating, Electrophoretic Deposition, Unidirectional Nanorods, and Soft Lithography}

Although sol-gel process is a well-known method to fabricate PZT thin films, there is plenty of room to improve the sol-gel process resulting in PZT thin films that offer bigger crackfree areas, larger thickness, extreme aspect ratios (e.g., nanorods), and arbitrary patterning. Some novel sol-gel-based processes are described as follows.

\section{Dilute Sealant Coating}

As shown in [36-38], traditional sol-gel process often leads to PZT films with thickness in the range of $15-100 \mathrm{~nm}$ per coating and crack-free area of $1 \mathrm{~mm}^{2}$. Especially for devices in the meso scale, it is very desirable to have the film thickness greater than $1 \mu \mathrm{m}$ and 


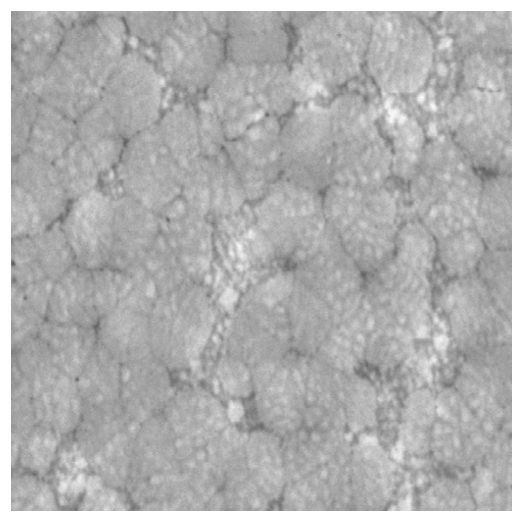

Figure 5. Surface of PZT film by SEM.

the crack-free area exceeding $25 \mathrm{~mm}^{2}$, which is a $5 \mathrm{~mm}$ by $5 \mathrm{~mm}$ square area. To achieve these dimension specifications, we fabricate the PZT thin films using an improved sol-gel process that adopts rapid thermal annealing and a dilute sealant coating. The philosophy is to use the rapid thermal annealing for the first two coatings to reduce thermal stresses. For the third coating, we used diluted sol to seal possible cracks formed in the previous coatings. With these improvements, we can achieve a film thickness of $2 \mu \mathrm{m}$ in 3 coatings (i.e., $670 \mathrm{~nm}$ per coating). Also, the PZT film surface is crack-free and smooth; see the SEM photo in Fig. 5. In general, typical crack free areas are about $5 \mathrm{~mm} \times 5 \mathrm{~mm}$. Compared with existing results in literature [36-38], this improved sol-gel process has increased the film thickness by $600 \%$ and the crack-free area by one order of magnitude! The detailed process is described as follows [45].

The silicon substrate is first oxidized in a furnace at $1045^{\circ} \mathrm{C}$ for 2 hours to grow a $\mathrm{SiO}_{2}$ layer of $5000 \AA$ thick. Then a layer silicon nitride of $5000 \AA$ thick is deposited by LPCVD (low-pressure chemical vapor deposition). The bottom electrode consists of Pt/Ti layers with thickness of $100 \mathrm{~nm}$ and $50 \mathrm{~nm}$, respectively. The PZT film is dip-coated or spin-coated three times. For the first two coatings, the sintering temperature is $650^{\circ} \mathrm{C}$ for 15 minutes. For the third coating, the sol is diluted $50 \%$ by acetic acid and sintering temperature is $450^{\circ} \mathrm{C}$ for 10 minutes. The top electrode consists of $\mathrm{Au} / \mathrm{Cr}$ layers through evaporation.

\section{Sol Electrophoresis}

One novel process that can substantially increase the thickness of PZT thin films to the range of $10 \mu \mathrm{m}$ is sol electrophoresis. Sol electrophoresis is essentially a combination of sol preparation and electrophoretic deposition. When a sol is appropriately prepared, it consists of nanometer-sized particles dispersed in a solvent and the surface of the solid particles is electrically charged. When an external electric field is applied to a sol, charged solid particles will migrate in response to the electric field; see Fig. 6. Such motion is known as electrophoresis. As a result, electrophoresis can be used to enrich and deposit solid particles onto a substrate, if the substrate serves as an electrode.

Compared with spin-coated or dip-coated films, PZT films from electrophoresis have much higher resistance to crack formation. For spin-coated or dip-coated films, the excessive capillary force during drying will induce significant stress gradients resulting in cracks. In contrast, electrophoretic deposition will result in high packing density of PZT particles 

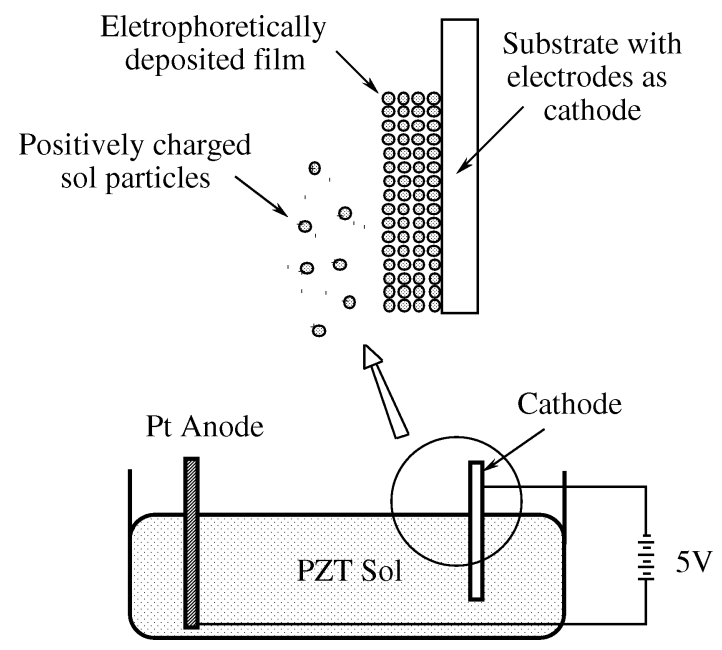

Figure 6. Electrophoretic deposition of PZT films.

(74\% in theory [46]). This will not only substantially reduce the chances for cracking during drying and sintering, but also allow more accurate control of the size and shape of the PZT films.

After the sol is prepared, PZT thin films were subsequently grown via electrophoresis; see Fig. 6. First, an anode of Pt mesh is immersed in the PZT sol. The cathode is the depositing substrate, i.e., silicon substrate coated with bottom electrodes. For the electrophoretic growth, a potential of $3 \mathrm{~V} / \mathrm{cm}$ is applied between the electrodes for 30 minutes. At the end of the electrophoretic deposition, excessive sol is blotted off the substrate. The substrate with the deposited film is air-dried for 15 minutes, and is subsequently placed in a $100^{\circ} \mathrm{C}$ drying oven overnight. Finally, the film is sintered in air at $750^{\circ} \mathrm{C}$ for 30 minutes with a ramping rate of $1^{\circ} \mathrm{C}$ per minute. X-ray diffraction analyses revealed that the resultant PZT thick films consist of perovskite phase only. Also, sharp diffraction peaks imply good crystallinity of the PZT thick film. Scanning electron microscopy revealed such thick PZT films can reach $20 \mu \mathrm{m}$ in thickness, but most films are delaminated from the substrate. Figure 7

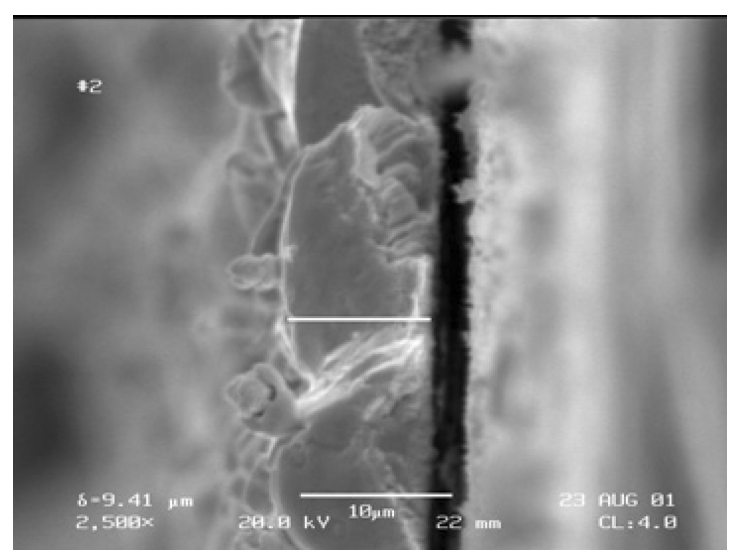

Figure 7. SEM image of PZT thick film (cross-sectional view). 


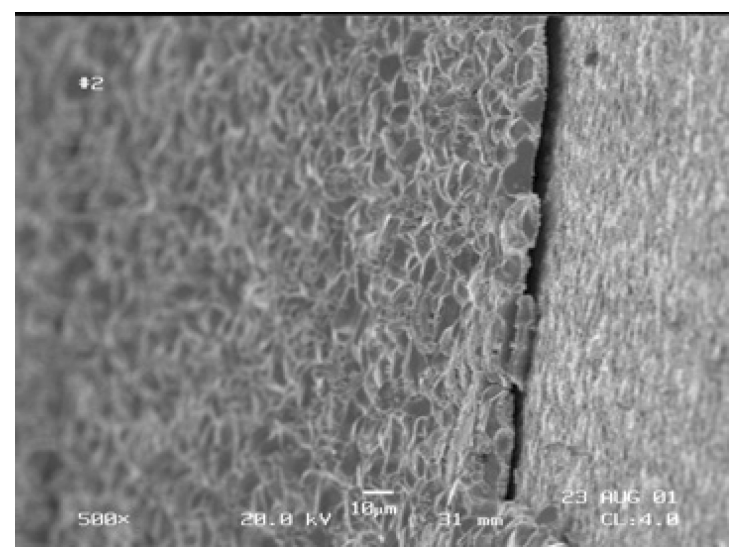

Figure 8. SEM images of PZT thick film (tilted film surface).

shows a typical SEM cross-sectional image of a PZT film on substrates. The image shows that the thickness is $10 \mu \mathrm{m}$. Figure 8 is an SEM image showing the titled film surface. The delamination of the thick PZT films is most likely caused by the big CTE mismatch of the PZT film and the bottom electrode.

\section{Unidirectional Nanorods}

Sol electrophoretic deposition can also be used to directly fabricate micro- and nanostructures with high aspect ratios. For example, unidirectionally aligned nanorod arrays can be synthesized by template-based growth in combination with sol electrophoretic deposition $[47,48]$. This method can form nanorods for a wide range of materials, such as metals and ceramics, including PZT. Figure 9 schematically illustrates the fabrication process. First, an anode of Pt mesh is immersed in the silica sol. The aluminum cathode is covered with a polycarbonate (PC) membrane via a double-stick carbon conductive tape. The PC

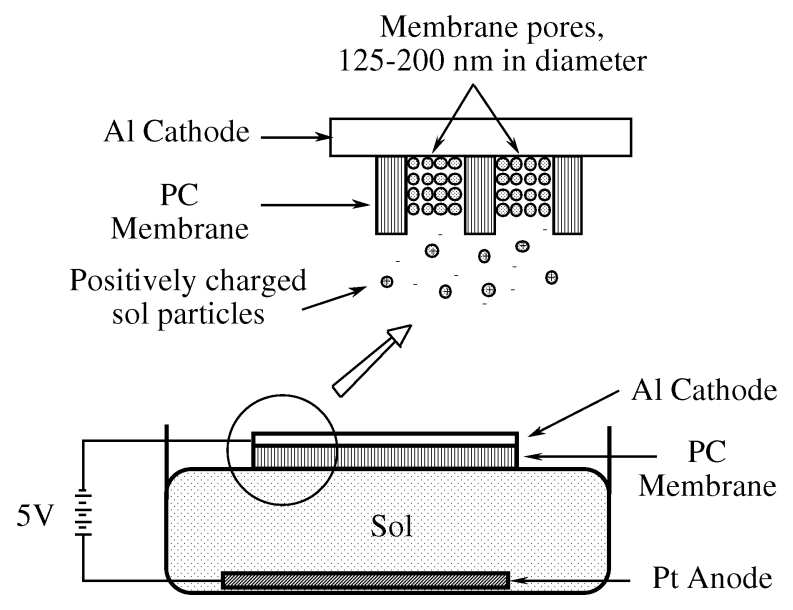

Figure 9. Fabrication process of nanorods. 


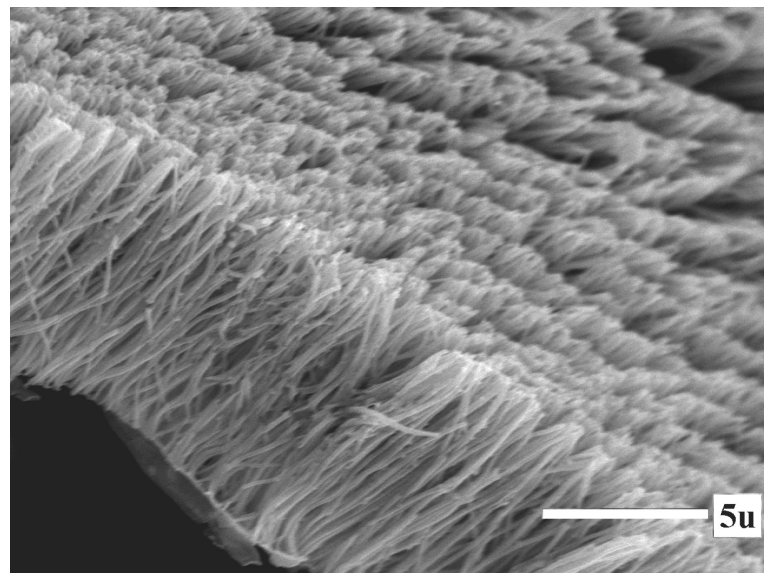

Figure 10. SEM photo of PZT nanorods.

membrane is porous, and the diameter of the pores can be selected from $50 \mathrm{~nm}$ to $500 \mathrm{~nm}$ or microns. The cathode is placed on top of the sol such that the PC membrane barely touches the sol. As a result, the sol is drawn into the pores through capillary action. For the electrophoretic growth, a voltage of $3 \mathrm{~V}$ is applied between the electrodes for 30-60 min. The electrophoretic potential pacts positively charged sol particles tightly into the pores of the PC membrane. At the end of the electrophoretic deposition, excessive sol is blotted off the membrane, and the sample is dried at $100^{\circ} \mathrm{C}$ for several hours and is sintered in an oven between $700^{\circ} \mathrm{C}$ and $800^{\circ} \mathrm{C}$ for $15-30$ minutes to densify and crystallize the nanorods as well as to burn off the PC membrane. Figure 10 shows the SEM photo of the unidirectionally aligned and uniformly sized PZT nanorods with a diameter of $200 \mathrm{~nm}$ and a length of $10 \mu \mathrm{m}$.

It should be noted that although the above example shows the ability of synthesis of unidirectionally aligned uniformly sized PZT nanorod arrays, sol electrophoretic deposition can be easily combined with deep X-ray Lithography $[49,50]$ and soft lithography $[51,52]$ to create various desired PZT patterns in both micro- and meso-scales. With sol electrophoretic deposition, the feature size of a pattern can be as small as a few tens nanometers and the aspect ratio can be at least above 1000 .

\section{Soft Lithography}

Since PZT thin films are ceramic, they are very difficult to pattern and etch. Although dry and wet etching recipes are available to pattern PZT films [53-55], there could be various problems such as slow etching rate and large feature size. One possible way to avoid patterning PZT thin films is to use soft lithography [51, 52]. Figure 11 illustrates the fabrication process of PZT thin films through use of sol-gel processing and soft lithography [56]. The pattern of the PZT thin films is in the form of parallel stripes. First, a positive master is created on a silicon wafer using standard semiconductor processing techniques (Fig. 11(a)). The master has parallel stripes whose cross sectional area is $2 \mu \mathrm{m}$ by $2 \mu \mathrm{m}$. The master is then covered with liquid polydimethylsiloxane (PDMS). When the PDMS is cured, the silicon and PDMS are separated. Therefore, a negative of the pattern is transferred to the PDMS in the form of parallel microchannels. The PDMS 
(a)

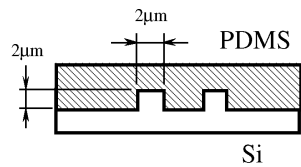

(c)

PZT sol-gel

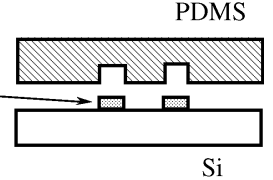

PDMS

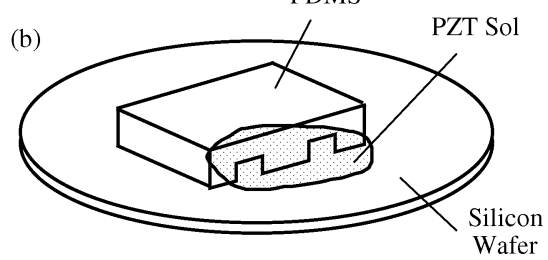

Figure 11. Soft lithography sol-gel method to deposit PZT thin films.

mold (i.e., the negative) is then cleaned with ethanol and placed in conformal contact with a clean silicon substrate (Fig. 11 (b)). The PZT sol is then deposited on the open ends of the microchannels. The capillary force gradually draws the PZT sol into the microchannels.

The PDMS mold and substrate are then placed in a drying oven for 24 hours at $100^{\circ} \mathrm{C}$. As the solvent evaporates, the condensation process facilitates cross-linking of individual clusters in PZT sol resulting in the sol-gel transition. The PDMS mold is then removed from the silicon substrate (Fig. 11(c)). Because PDMS has a relatively low surface energy, the PZT sol-gel stays on the silicon substrate forming a positive replica of the PDMS mold. Finally, the patterned PZT/silicon structure is sintered at $700^{\circ} \mathrm{C}$ for 30 minutes to densify PZT and to form the desired phase. Figure 12 shows the topography of the PZT/silicon structure obtained through atomic force microscopy. The humps in Fig. 12 are patterned PZT structures.

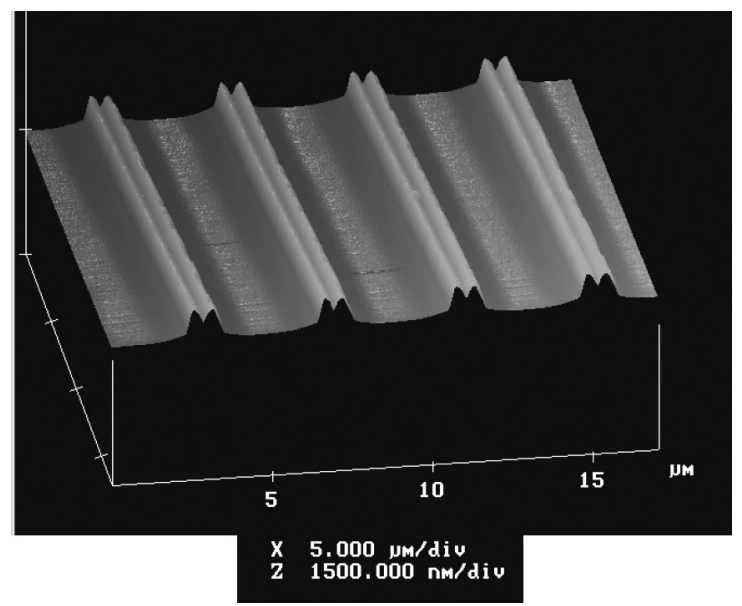

Figure 12. Topography of PZT/silicon via AFM. (See Color Plate VII) 


\section{Design Considerations for PZT Thin-Film Actuators: Measurements of Piezoelectric Properties, Effects of Corner Frequency, and Finite Element Analysis}

PZT thin-film actuators have wide applications, such as atomic force microscopes (AFM) [57, 58], ultrasonic micromotors [59-62], one- or two-dimensional scanners [63-65], microswitches [66], resonators $[67,68]$, and dual-stage actuators/sliders for next-generation computer hard disk drives $[1,18,69-70]$. When PZT thin films are incorporated in a mesoor micro-actuator, there are many design challenges to overcome. As described earlier, the PZT film thickness is usually less than several microns as opposed to hundreds of microns for bulk PZT patches that are commercially available. As a result, PZT thin-film actuators pose unique design issues that do not appear in actuators with bulk PZT. These issues are explained in detail as follows.

\section{Piezoelectric Properties of PZT Thin Films}

Since PZT thin films produce only minute displacement when actuated, the displacement often needs to be amplified mechanically in order to make a PZT thin-film actuator useful. The most common design adopts a beam- or plate-like structure, so that the tiny in-plane motion of the PZT films can be converted to a much larger out-of-plane motion of the structure. As a result, one often needs to know the Young's modulus $E$ and piezoelectric constant $d_{31}$ (not $d_{33}$ ) in designing PZT thin-film actuators. Unfortunately, measuring $E$ and $d_{31}$ separately is a difficult task; therefore, $e_{31}$ is often measured instead. Currently, direct and accurate measurements are available for $d_{33}$ [71] but not for $e_{31}$ [72-74].

Traditional methods to measure $e_{31}$ include the following steps. First, PZT film is deposited on specimens that take the form of cantilevers [72], simply supported beams [73], or plates [74]. Second, a known load is applied to the specimens and the charge accumulated in the PZT film is measured. According to mechanics of materials, one can calculate the strain developed in the film assuming perfect boundary conditions (e.g, fixed). The ratio of the measured charge to the calculated strain gives $e_{31}$ of the film. Since the real boundary conditions of the specimen are not perfect, the strain predicted from the perfect boundary conditions often results in inaccurate $e_{31}$.

Figure 13 shows an experimental setup to directly measure $e_{31}$ of PZT thin films regardless of the boundary conditions of the specimens [45]. The experimental setup (Fig. 13)

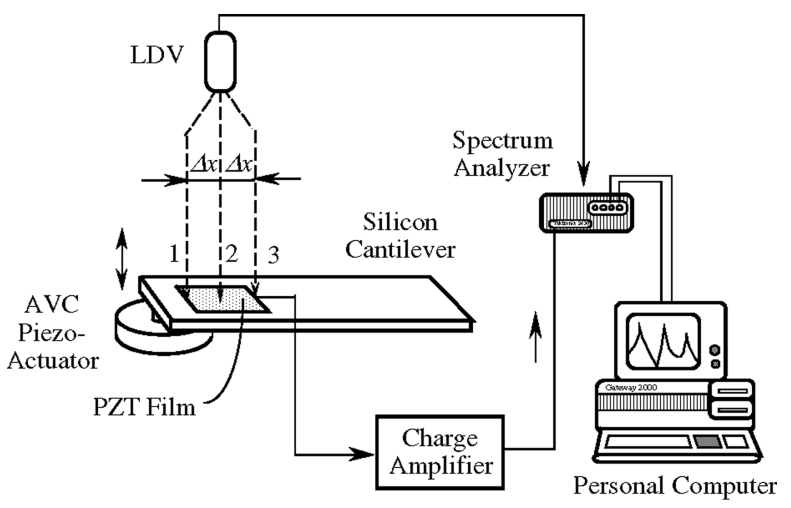

Figure 13. Experimental setup to calibrate PZT thin film as a sensor. 


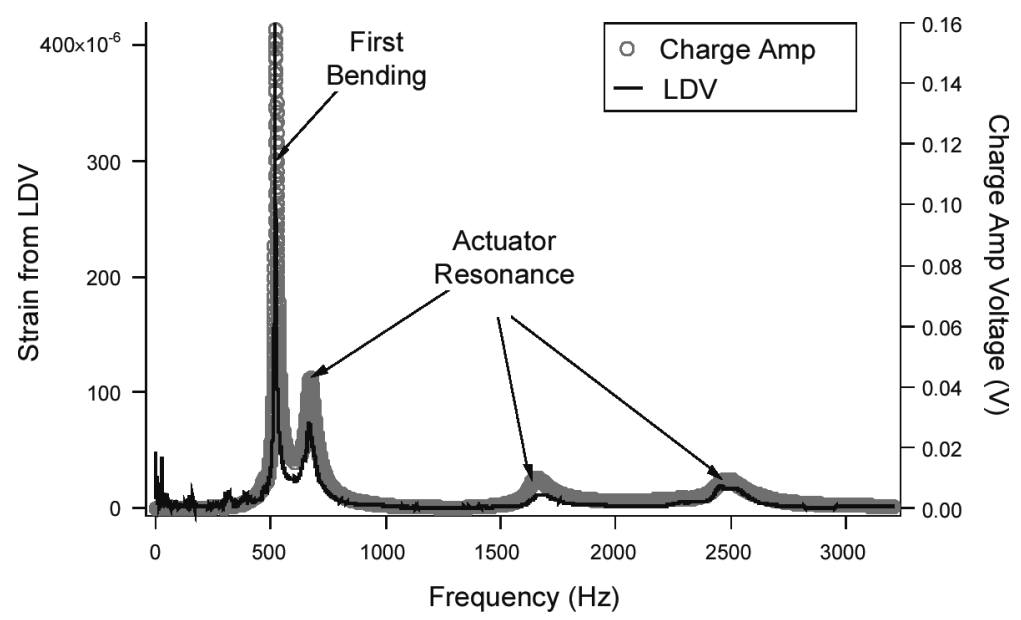

Figure 14. Calibration of PZT thin-film sensor using an LDV. (See Color Plate VIII)

consists of a silicon beam with a PZT film excited by a tiny shaker. A charge amplifier detects the charge accumulated in the PZT film. A spectrum analyzer processes the charge amplifier's output to obtain a frequency spectrum. In addition, three calibration points are defined along the PZT film as 1,2 , and 3 . These points are evenly spaced with distance $\Delta x$. A laser Doppler vibrometer (LDV) measures the deflection $w_{1}, w_{2}$, and $w_{3}$ of the calibration points 1, 2, and 3. According to Euler-Bernoulli beam theory, the normal strain is $\varepsilon \approx 0.5 h\left(w_{1}-2 w_{2}+w_{3}\right) /(\Delta x)^{2}$, where $h$ is the thickness of the cantilever. Finally, the ratio of the charge to the strain $\varepsilon$ gives $e_{31}$. Note that this approach does not depend on the boundary conditions of the specimen. Therefore, the boundary conditions do not affect the accuracy of the measurements.

Figure 14 compares the charge amplifier output voltage and the strain measurements. Note that the charge amp voltage refers to the right axis in Fig. 14. The dimensions of the silicon cantilever and the PZT film are $30 \mathrm{~mm} \times 7.5 \mathrm{~mm} \times 0.4 \mathrm{~mm}$ and $4 \mathrm{~mm} \times 4 \mathrm{~mm} \times 1 \mu \mathrm{m}$, respectively. The capacitance of the PZT film is $40 \mathrm{nF}$. The first resonance peak at $520 \mathrm{~Hz}$ is the first bending mode of the cantilever. Also, the charge amp has a gain of 4.4. Using the amplitude at $520 \mathrm{~Hz}, e_{31}=(0.16 / 4.4) /\left(4.2 \times 10^{-4}\right) \times\left(44 \times 10^{-9}\right) /\left(16 \times 10^{-6}\right)=0.24 \mathrm{C} / \mathrm{m}^{2}$, which is in the same order of $e_{31}$ reported in the literature.

\section{Effects of Corner Frequency}

Functionally, PZT thin-film actuators can be classified as broadband actuators and singlefrequency actuators. Figure 15 shows a frequency response function (FRF) explaining the differences of these two types of actuators. Broadband actuators operate over a wide range of frequency, in which the frequency response function is approximately constant. In this frequency range, the actuator output motion is proportional to the input voltage without significant distortion. The bandwidth of the actuator is often defined as the frequency range in which the FRF has less than 3-db variation to minimize possible input-output distortion. Applications of broadband actuators include AFM and microswitches for example. In this case, maximizing the bandwidth is a major design consideration because it determines how fast the tip of AFM can tap and how fast a microswitch can open and close. In contrast, single-frequency actuators operate at a single frequency, usually at a natural frequency of 


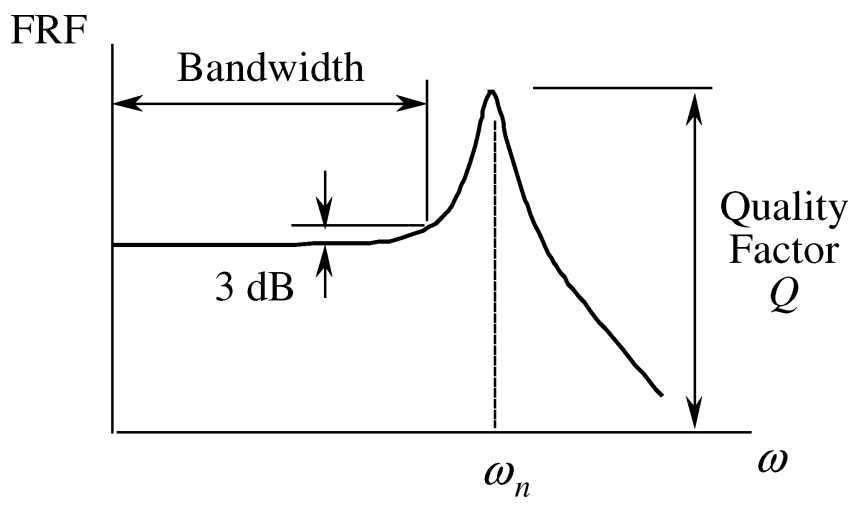

Figure 15. Frequency response function of broadband and single-frequency actuators.

the actuator's mechanical structure. Example applications include resonators and scanners. In these applications, the resonance amplitude - known as quality factor $Q$-is very critical. Large $Q$ implies that a scanner can have a large scanning angle for example.

Since PZT thin-film actuators are electromechanical devices, the actuators' performance indexes, such as bandwidth and quality factor, depend not only on the actuators' mechanical structures but also on actuators' circuit design. Mechanically, the structure is a spring-mass-damper system characterized by the lowest natural frequency $\omega_{n}$. Electrically, the circuit forms a low-pass $R C$ filter characterized by its corner frequency $\omega_{c} \equiv 1 / R C$, where $R$ is the resistance of the circuit and $C$ is the capacitance of the PZT thin film. For actuators employing bulk PZT, $\omega_{c}$ is often a couple of orders higher than $\omega_{n}$. Therefore, the actuator bandwidth and quality factor are primarily dominated by the mechanical resonance frequency $\omega_{n}$ and the system's damping, respectively.

For PZT thin-film actuators, however, $\omega_{c}$ could be a couple of orders-of-magnitude less than $\omega_{n}$ due to the tiny thickness of PZT films. As a result, the capacitance $C$ of PZT thin films is significantly larger than that of bulk PZT on a per area basis, and the corner frequency $\omega_{c}$ of PZT thin-film actuators is reduced dramatically. As the size of PZT thin-film actuators decreases, $\omega_{n}$ increases significantly. Therefore, improper design of PZT thin-film actuators could lead to $\omega_{c} \ll \omega_{n}$ substantially reducing the actuator bandwidth and quality factor.

Figure 16 shows the frequency response function (FRF) of two PZT thin-film actuators with different corner frequencies [75]. The two actuators have the same mechanical structure, i.e., a silicon beam fixed at both ends with a span of $6 \mathrm{~mm}$. In addition, the width and the thickness of the silicon beam are $7.5 \mathrm{~mm}$ and $0.4 \mathrm{~mm}$, respectively. As a result, the lowest natural frequency of the silicon beam is $\omega_{n}=50.92 \mathrm{kHz}$. The two actuators, however, have different circuit resistance. One has a low resistance of $0.3 \Omega$ resulting in an extremely high corner frequency $\omega_{c}=1.326 \mathrm{MHz}$. In contrast, the other actuator has a high resistance of $480 \Omega$ resulting in a low corner frequency $\omega_{c}=8.289 \mathrm{kHz}$. In Fig. 16, the thick solid line represents the FRF of the actuator with low resistance. In this case, $\omega_{c} \gg \omega_{n}$; therefore, the FRF starts with a constant magnitude and is followed by a resonance peak at $\omega_{n}$. The 3-dB bandwidth is roughly $23.716 \mathrm{kHz}$. In contrast, the thin solid line in Fig. 16 represents the FRF of the actuator with high resistance. In this case, $\omega_{c} \ll \omega_{n}$. As a result, the FRF starts with a constant magnitude at low frequency, but the magnitude rapidly decreases as the driving frequency increases. The $3-\mathrm{dB}$ bandwidth is roughly $9.548 \mathrm{kHz}$. In other words, the bandwidth has reduced by $59.74 \%$ as a result of the high electrical resistance. Moreover, the quality factor has a reduction of one order of magnitude. 


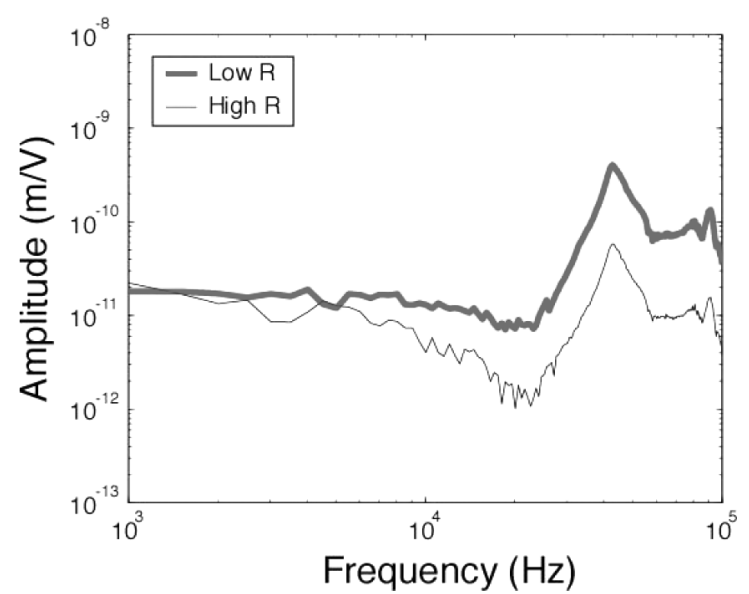

Figure 16. Frequency response function of actuators with small and large corner frequencies. (See Color Plate IX)

\section{Finite Element Analysis and Vibration Testing}

A major design tool to analyze vibration of PZT thin-film actuators is finite element analysis (FEA). When compared with experimental measurements, uncertainties in boundary conditions and piezoelectric constants can substantially reduce the accuracy of FEA. Here is an example [76].

Figure 17 shows a conceptual design of a PZT thin-film actuator for 2-D actuation. The design consists of a silicon suspension, a PZT thin film with electrodes on the suspension, and the silicon substrate. Figure 18 shows the layout of the PZT thin film (from bottom view of Fig. 17) to perform the 2-D actuation. The PZT film has four independent actuators $A, B, C$, and $D$ as indicated by the square in Fig. 18 . When actuators $(A, B)$ are in phase, $(C, D)$ are in phase, but $(A, B)$ and $(C, D)$ are out of phase, the suspension will rock the centerline (i.e., $z$ axis) about the $y$ axis with an angle $\theta_{y}(t)$; see Fig. 18. Similarly, when actuators $(A, D)$ are in phase, $(B, C)$ are in phase, but $(A, D)$ and $(B, C)$ are out of phase,

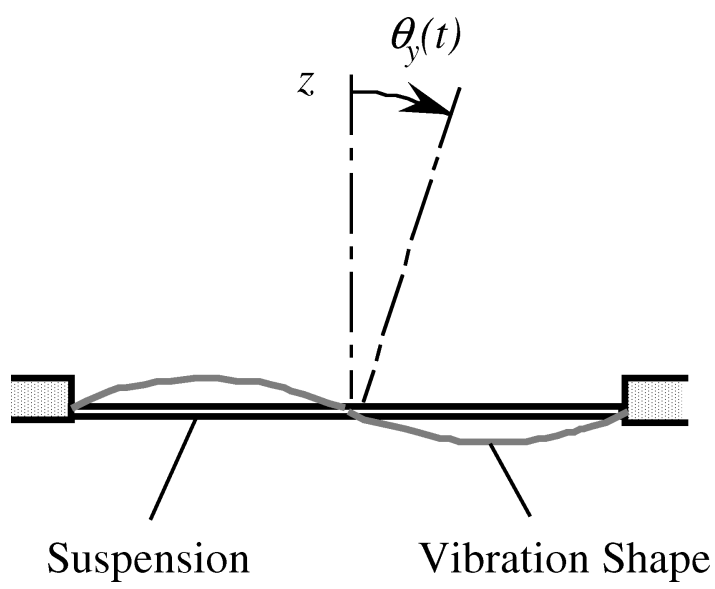

Figure 17. A design of a 2-D actuator. 


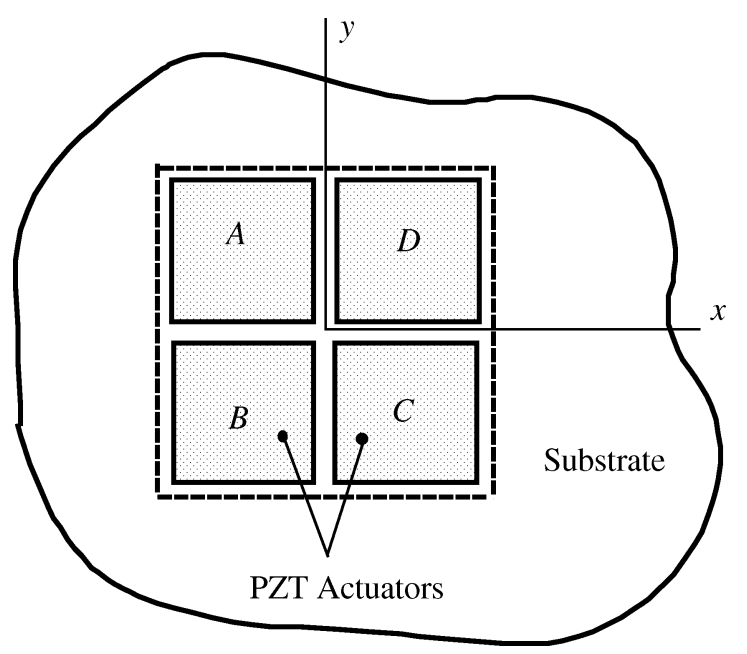

Figure 18. Layout of the PZT actuators.

the suspension will rock the centerline about the $x$ axis. When $A, B, C, D$ are driven in sequence as in a DC motor, the centerline will wobble and cause a circular scanning motion about the $z$ axis. Therefore, by controlling the voltage and phase into the four actuators $A$, $B, C, D$, we can orient the centerline (i.e., $z$-axis) arbitrarily in a two-dimensional manner.

A prototype of the 2-D actuator is fabricated using the following steps. First, the front side of the silicon substrate (Si wafers with $400-\mu$ m thickness) is first deposited with a PZT thin film using the rapid thermal annealing and dilute sealant layer described above. The film thickness is about $1 \mu \mathrm{m}$. Also, the $\mathrm{Au} / \mathrm{Cr}$ top electrodes are deposited through evaporation. Second, the backside of the substrate is patterned and etched with deep reactive ion etching (RIE) for $300 \mu \mathrm{m}$ to form the suspension. The suspension dimension is $14 \mathrm{~mm}$ by $14 \mathrm{~mm}$.

To measure the vibration characteristics of the 2-D actuator, the actuator is first bonded to aluminum blocks on both edges via double stick tapes. A spectrum analyzer drives one of the four PZT actuators shown in Fig. 18 in the form of swept sines from low to high frequency. In the meantime, a laser Doppler vibrometer (LDV) measures the vibration of the suspension. The spectrum analyzer processes the driving voltage and the LDV

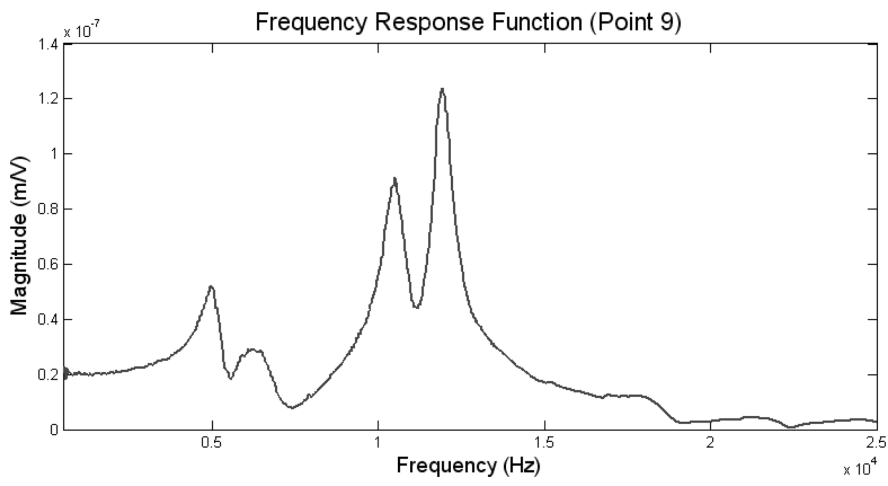

Figure 19. Measured FRF at the driving electrode. 
Table 1

Comparison of predicted and measured natural frequencies;

$$
E_{T}=3 \mathrm{GPa}
$$

\begin{tabular}{lccc}
\hline Mode & Mode Type & Measured $(\mathrm{Hz})$ & FEA $(\mathrm{Hz})$ \\
\hline 1 & 0 nodal line & $5290 \mathrm{~Hz}$ & $5562 \mathrm{~Hz}$ \\
2 & 1 nodal line & $9400 \mathrm{~Hz}$ & $9976 \mathrm{~Hz}$ \\
3 & 1 nodal line & $10810 \mathrm{~Hz}$ & $11939 \mathrm{~Hz}$ \\
\hline
\end{tabular}

measurements to produce frequency response function (FRF). Figure 19 shows the FRF measured at the driving electrode. The FRF shows a constant gain of $20.6 \mathrm{~nm} / \mathrm{V}$ when the driving frequency is significantly less than the first natural frequency. If the bandwidth is defined as $3 \mathrm{~dB}$ increase in FRF gain at $0 \mathrm{~Hz}$, the bandwidth is $4005 \mathrm{~Hz}$.

A finite element model is created to predict the bandwidth and the gain measured in the experiments. The finite element model consists of elastic solid elements for the suspension and the substrate as well as piezoelectric solid elements for the PZT thin film. Since the actuator is bonded to two aluminum blocks via tapes, the boundary conditions at the tapes are modeled as elastic layers with an unknown Young's modulus. Figure 20 shows how natural frequencies of the prototype predicted from FEA vary with respect to the tape Young's modulus $E_{T}$. Note that the natural frequencies and the order of vibration modes can change significantly when the tape stiffness is small. When $E_{T}$ is around $3 \mathrm{GPa}$, the predicted natural frequencies agree well with experimental measurements within 5\%. Table 1 shows the comparison of the theoretical and experimental results on natural frequencies.

Similarly, Fig. 21 shows how the actuator gain varies with respect to the Young's modulus $E_{T}$ at the driving point of the actuator. Note that the actuator gain starts to increase substantially when $E_{T}$ is below $3 \mathrm{GPa}$. (This fact manifests itself the importance of the boundary conditions.) Table 2 shows the comparison of the predicted and measured actuator gains at 5 sample points when $E_{T}$ is $3 \mathrm{GPa}$. In general, the predicted gains from FEA are about twice of those measured in the experiments. The difference primarily comes from uncertainties of piezoelectric constants in PZT thin films. In FEA, piezoelectric constants of bulk PZT are used as references. In reality, piezoelectric constants of PZT thin films are substantially less than those in bulk PZT, because PZT films have smaller grain size. Finally, Fig. 22 compares the deformed actuator contour as measured from the experiment

Table 2

Comparison of predicted and measured actuator gain; $E_{T}=3 \mathrm{GPa}$

\begin{tabular}{lcc}
\hline Point & $\begin{array}{c}\text { Measured } \\
(\mathrm{nm} / \mathrm{V})\end{array}$ & FEA (nm/V) \\
\hline 1 & 20.8 & 43.5 \\
2 & 17.4 & 32.8 \\
3 & 20.6 & 43.5 \\
4 & 18.3 & 36.3 \\
5 & 6.04 & 8.53 \\
\hline
\end{tabular}




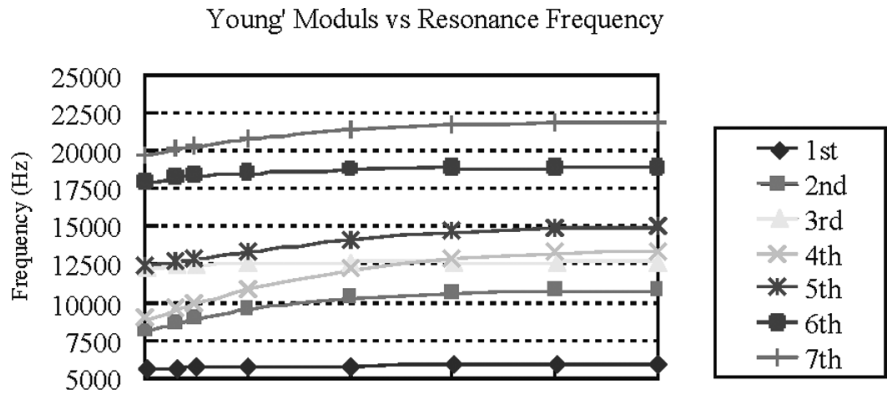

1.E+07 1.E+08 1.E+09 1.E+10 1.E+11 1.E+12

Young's Modulus (N/m2)

Figure 20. Variation of natural frequencies with $E_{T}$. (See Color Plate X)

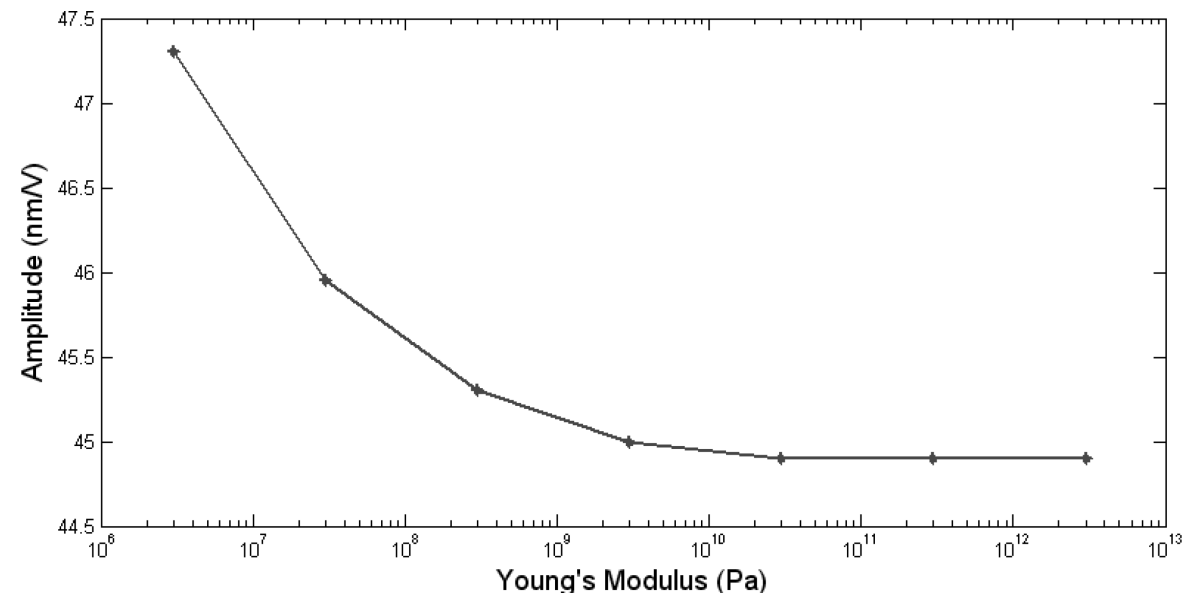

Figure 21. Calculated gain with respect to $E_{T}$.
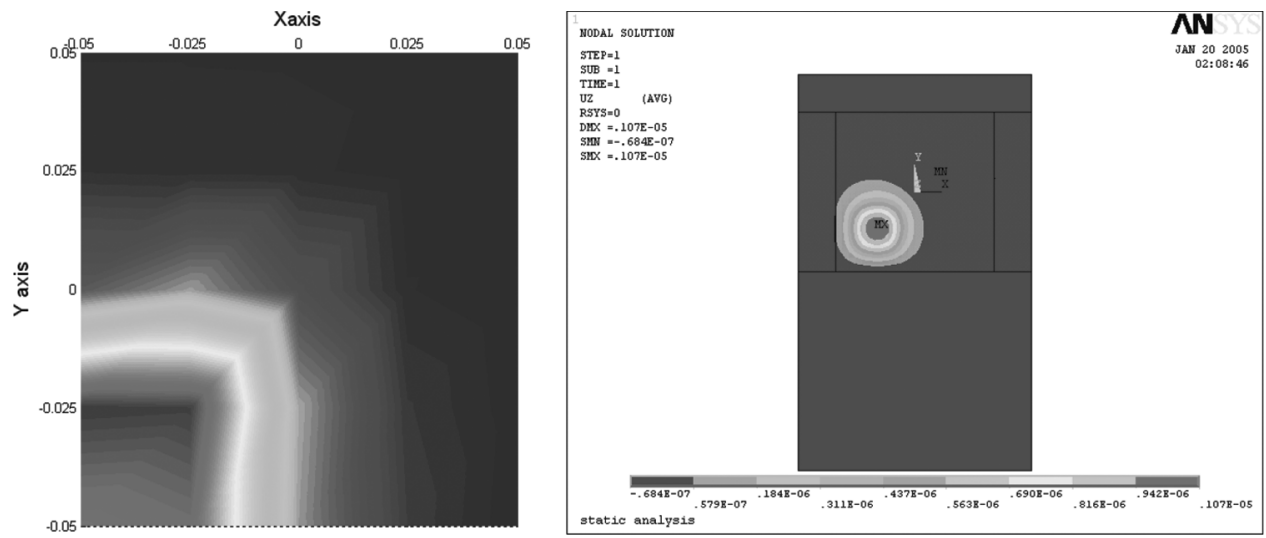

Figure 22. Deformed actuator contours; experiment (left) vs. FEA (right). (See Color Plate XI) 
and predicted from FEA. Both contour plots show the same qualitative behavior, i.e., the deformation is localized at the lower left corner of the suspension.

\section{Conclusions}

This paper reviews fabrication challenges of sol-gel-derived PZT thin films, novel solgel processes to improve quality of PZT thin films, and design issues often encounter in PZT thin-film actuators. Current challenges include small film thickness each coating, small crack-free area (i.e., crack formation), thermally unstable metal electrodes, and poor piezoelectric properties. Some recent and novel sol-gel processes include dilute sealant coating to increase crack-free area, sol electrophoresis to produce arrays of uniform and unidirectional PZT nanorods, and soft lithography to pattern PZT films without etching. As far as design of PZT thin-film actuators, one needs to confirm that the corner frequency of the PZT $R C$-circuit is much higher than the lowest natural frequency of the actuator's mechanical structure, so that the bandwidth and quality factor will not be sacrificed. Also, accuracy of finite element analyses cannot be readily assumed, because uncertainties in piezoelectric constants and boundary conditions can significantly alter the predictions from the finite element analyses.

\section{References}

1. K. Suzuki, R. Maeda, J. Chu, T. Kato, and M. Kurita, IEEE Transaction on Magnetics 39, 826 (2003).

2. Sze SM: Semiconductor Sensors. New York: John Wiley \& Sons, Inc.; 1994.

3. D. L. Polla and L. F. Francis, Annual Reviews of Material Science 28, 563 (1998).

4. P. Muralt, Journal of Micromechanics and Microengineering 10, 136 (2000).

5. E. J. Seibel, M. Fauver, J. Crossman-Bosworth, Q. Y. L. Smithwick, and C. M. Brown, Proceedings of SPIE 4957, 46 (2003).

6. P. Krulevitch, A. P. Lee, P. B. Ramsey, J. C. Trevino, J. Hamilton, and M. A. Northrup, Journal of Microelectromechnical Systems 5, 270 (1996).

7. E. S. Kolesar, P. B. Allen, J. T. Howard, J. M. Wilken, and N. Boydston, Thin Solid Films 355, 295 (1999).

8. J. W. Judy, T. Tamagawa, and D. L. Polla, Technical Digest of Electron Devices Meeting, 629 (1990).

9. L. Que, J. S. Park, and Y. B. Gianchandani, Proceedings of Twelfth IEEE International Conference on Micro Electro Mechanical Systems, 31 (1999).

10. R. Cragun and L. L. Howell, ASME 1999 International Mechanical Engineering Congress and Exposition MEMS 1, 181 (1999).

11. W. C. Tang, T. H. Nguyen, and R. T. Howe, Proceedings IEEE Mcro Elctro Mechanical Systems, pp. 53-59 (1989).

12. W. C. Tang, T. H. Nguyen, M. W. Judy, and R. T. Howe, Proceedings of the 5th International Conference on Solid-State Sensors and Actuators and Eurosensors III, 2, 328 (1990).

13. N. A. Riza, D. L. Polla, W. P. Robbins, and D. E. Glumac, Electron Letters 29, 1606 (1993).

14. P. Muralt, A. Kholkin, M. Kohli, and T. Maeder, Sensors and Actuator A-Physical 53, 398 (1996).

15. P. Luginbuhl, G. A. Racine, P. Lerch, B. Romanowicz, K. G. Brooks, N. F. deRooij, and P. Renaud, Sensors and Actuator A-Physical 54, 530 (1996).

16. P. Muralt, Integrated Ferroelectrics 17, 297 (1997).

17. http://www.morganelectroceramics.com

18. H. Kuwajima, H. Uchiyama, Y. Ogawa, H. Kita, and K. Matsuoka, IEEE Transaction on Magnetics 38, 2156 (2002). 
19. T. S. Kim, D. J. Kim, J. K. Lee, and H. I. Jung, Ferroelectric Thin Films V. Symposium. Mater. Res. Soc. 243 (1995).

20. T. Hata, S. Kawagoe, W. Zhang, K. Sasaki, and Y. Yoshioka, Vacuum 51, 665 (1998).

21. R. Bruchhaus, D. Pitzer, R. Primig, M. Schreiter, and W. Wersing, Integrated Ferroelectrics 21, 461 (1998).

22. T. Sakoda, K. Aoki, S. Hashimoto, and Y. Fukuda, Integrated Ferroelectrics 21, 385 (1998).

23. I. Novotny, P. Sutta, F. Mika, and V. Tvarozek, Proceedings of 20th International Conference on Microelectronics 1, 65 (1995).

24. K. Eda, Y. Tomita, M. Sugimoto, A. Nanba, T. Ogura, Y. Taguchi, and O. Kawasaki, Proceedings of IEEE Ultrasonics Symposium 2, 921 (1995).

25. K. Eda, Y. Tomita, M. Sugimoto, T. Ogura, A. Nanba, Y. Taguchi, and O. Kawasaki, Proceedings of the Tenth IEEE International Symposium on Applications of Ferroelectrics 2, 719 (1996).

26. S. P. Beeby, and N. M. White, Proceedings of the Tenth Conference on Sensors and their Applications, 131 (1999).

27. R. Maas, M. Koch, N. R. Harris, N. M. White, and A. G. R. Evans, Material Letters 31, 1 (1997).

28. C. Y. Pan, Y. L. Chen, and D. S. Tsai, Journal of Material Research 17, 1536 (2002).

29. G. Yi and M. Sayer, Proceedings of the Eighth IEEE International Symposium on Applications of Ferroelectrics, 289 (1992).

30. M. D. Liu, C. R. Lu, P. Y. Wang, Y. H. Rao, Y. K. Zeng, and C. R. Li, Sensors and Actuators A-Physical 49, 191 (1995).

31. K. G. Brooks, I. M. Reaney, T. Maeder, and N. Setter, Electroceramics. Aachen: Verlag der Augustinus Buchhandlung, 1994.

32. W. I. Lee, J. K. Lee, I. Chung, C. W. Chung, I. K. Yoo, and S. B. Desu, Proceedings of Fourth Symposium on Ferroelectric Thin Films, 421 (1995).

33. M. Sayer, G. Yi, and M. Sedlar, Integrated Ferroelectrics 7, 1 (1995).

34. L. Cakare, B. Malic, and M. Kosec, Proceedings of 34th International Conference on Microelectronics, Devices and Materials, 349 (1998).

35. K. Miyazawa, K. Ito, and R. Maeda, Ceramics International 26, 501 (2000).

36. P. Luginbuhl, S. D. Collins, G. A. Racine, M. A. Gretillat, N. F. deRooij, K. G. Brooks, and N. Setter, Journal of Microelectromechanical Systems 6, 337 (1997).

37. S. Y. Chen and C. L. Sun, Journal of Applied Physics 90, 2970 (2001).

38. H. Kueppers, T. Leuerer, U. Schnakenberg, W. Mokwa, M. Hoffmann, T. Schneller, U. Boettger, and R. Waser, Sensors and Actuators A-Physical 97-98, 680 (2002).

39. Hsu YC, Damping Treatments for Microstructures, PhD Dissertation, the University of Washington, 2003.

40. D. J. Jung, M. Dawber, A. Ruediger, J. F. Scott, H. H. Kim, and K. Kim, Applied Physics Letters 81, 2436 (2002).

41. B. Vilquin, B. G. Le Rhun, R. Bouregba, G. Poullain, and H. Murray, Applied Surface Science 195, 63 (2002).

42. S. H. Kim, D. Y. Park, H. J. Woo, D. S. Lee, and J. Ha, Journal of Material Research 17, 1735 (2002).

43. A. J. Moulson and J. M. Herbert, Electroceramics: materials, properties, applications, London: Chapman and Hall; 1990.

44. W. L. Warren, D. Dimos, and R. M. Waser, MRS Bulletin 21, 40 (1996).

45. Y. C. Hsu, C. C. Wu, C. C. Lee, G. Z. Cao, and I. Y. Shen, Sensors and Actuators A-Physical 116, 367 (2004).

46. J. W. Evans and L. C. De Jonghe, The Production of Inorganic Materials. New York: Macmillan Publishing Company; 1991.

47. S. J. Limmer, S. Seraji, M. J. Forbess, Y. Wu, T. P. Chou, C. Nguyen, and G. Cao, Advanced Materials 13, 1269 (2001).

48. S. J. Limmer, S. Seraji, Y. Wu, T. P. Chou, C. Nguyen, and G. Cao, Advanced Functional Materials 12, 59 (2001).

49. H. Guckel, Proc. IEEE 8, 1586 (1993). 
50. B. Lochel, A. Maciossek, H. J. Quenzer, and B. Wagner, Journal of Electrochemical Society 143, 237 (1996).

51. Y. Xia and G. M. Whiteside, Annual Review of Materials Science 28, 153 (1998).

52. W. S. Beh, I. T. Kim, D. Qin, Y. Xia, and G. M. Whiteside, Advanced Materials 11, 1038 (1999).

53. S. E. Trolier, Q. C. Xu, and R. E. Newnham, IEEE Transactions on Ultrasonics, Ferroelectrics and Frequency Control 35, 839 (1988).

54. R. A. Miller and J. J. Bernstein, Integrated Ferroelectrics 29, 225 (2000).

55. W. Liu, J. Ko, and W. Zhu, Journal of Materials Science Letters 19, 2263 (2000).

56. S. Seraji, Y. Wu, N. E. Jewell-Larson, M. J. Forbess, S. Limmer, T. P. Chou, G. Cao, Advanced Materials 12, 1421 (2000).

57. H. Kueppers, T. Leuerer, U. Schnakenberg, W. Mokwa, M. Hoffmann, T. Schneller, U. Boettger, and R. Waser, Sensors and Actuator A-Physical 97, 690 (2002).

58. T. Shibata, K. Unno, E. Makino, and S. Shimada, Sensors and Actuators A-Physical 114, 398 (2004).

59. A. M. Flynn, L. S. Tavrow, S. F. Bart, R. A. Brooks, D. J. Ehrlich, K. R. Udayakumar, and L. E. Cross, Journal of Microelectromechanical Systems 1, 44 (1992).

60. P. Muralt, M. Kohli, T. Maeder, A. Kholkin, K. Brooks, N. Setter, and R. Luthier, Sensors and Actuators A-Physical 48, 157 (1995).

61. P. Muralt, A. Kholkin, M. Kohli, and T. Maeder, Sensors and Actuators A-Physical 53, 398 (1996).

62. M. Dubois and P. Muralt, IEEE Transactions on Ultrasonics, Ferroelectrics, and Frequency Control 45, 1169 (1998).

63. H. Goto, Proceedings of SPIE Conference on Optoelectronic Materials and Devices 3419, 227 (1998).

64. A. Schroth, C. Lee, S. Matsumoto, and R. Maeda, Sensors and Actuators A-Physical 73, 144 (1999).

65. J. Tsaur, L. Zhang, R. Maeda, S. Matsumoto, and S. Khumpuang, Japanese Journal of Applied Physics 41, 4321 (2002).

66. S. J. Gross, S. Tadigadapa, T. N. Jackson, S. Trolier-McKinstry, and Q. Q. Zhang, Applied Physics Letters 83, 174 (2003).

67. Q. Q. Zhang, S. J. Gross, S. Tadigadapa, T. N. Jackson, F. T. Djuth, and S. Trolier-McKinstry, Sensors and Actuators A-Physical 105, 91 (2003).

68. F. F. C. Duval, R. A. Dorey, R. W. Wright, Z. Huang, and R. W. Whatmore, IEEE Transactions on Ultrasonics, Ferroelectrics, and Frequency Control 51, 1255 (2004).

69. H. Kuwajima and K. Matsuoka, Thin-film piezoelectric DSA for HDD. IEEE Transaction on Magnetics 38, 2186 (2002).

70. N. Tagawa, K. Kitamura, and A. Mori, IEEE Transactions on Magnetics 39, 926 (2003).

71. K. Lefki and G. J. M. Dormans, Journal of Applied Physics 76, 1764 (1994).

72. M. A. Dubois and P. Muralt, Sensors \& Actuators A-Physical 77, 106 (1999).

73. A. Barzegar, D. Damjanovic, N. Ledermann, and P. Muralt, Journal of Applied Physics 93, 4756 (2003).

74. J. F. Shepard Jr., P. J. Moses, S. Trolier-McKinstry, Sensors \& Actuators A-Physical 71, 133 (1998).

75. C. C. Wu, C. C. Lee, G. Z. Cao, and I. Y. Shen, Sensors \& Actuators A-Physical (under review).

76. C. C. Lee, C. C. Wu, G. Z. Cao, and I. Y. Shen, Proceedings of 3rd Annual IEEE EMBS Special Topic Conference on Microtechnologies in Medicine and Biology (2005). 